\title{
Association between serum adipocyte fatty-acid binding protein concentrations, left ventricular function and myocardial perfusion abnormalities in patients with coronary artery disease
}

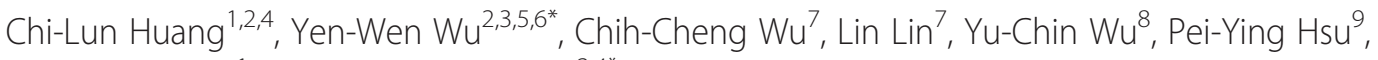
Yuh-Shiun Jong ${ }^{1}$ and Wei-Shiung Yang ${ }^{2,4^{*}}$

\begin{abstract}
Background: Adipokines, including adipocyte fatty acid-binding protein (A-FABP), have been demonstrated to be involved in the pathogenesis of atherosclerosis. In the present study, we investigated the association of circulating A-FABP level with severity of myocardial perfusion abnormalities analyzed by TI-201 dipyridamole single-photon emission computed tomography.

Methods: A total of 170 patients with coronary artery disease (CAD) from cardiovascular clinics were enrolled in the study. Serum A-FABP levels, echocardiography, and stress myocardial perfusion imaging results were analyzed.

Results: Compared with the patients with mild CAD (summed stress score [SSS] $\leq 8$ ), those with moderate to severe CAD (SSS > 8) had significantly higher A-FABP concentrations. However, the difference was attenuated in the subgroup of patients with heart failure. In the correlation analyses, A-FABP level was correlated with age, body mass index, waist circumference, levels of creatinine, fasting glucose, high-sensitivity C-reactive protein, N-terminal pro-brain natriuretic peptide, adiponectin, and several echocardiographic parameters, including left ventricular ejection fraction. Multivariate logistic regression analysis demonstrated that the A-FABP level was not only associated with higher SSS (odds ratio, 1.30; 95\% confidence interval [CI], 1.01-1.69; $P=0.048$ ), but also an independent risk factor for heart failure (odds ratio $2.71,95 \% \mathrm{Cl}, 1.23-5.94 ; P=0.013$ ).
\end{abstract}

Conclusions: Serum A-FABP levels not only were associated with myocardial perfusion abnormalities and left ventricular function, but also predicted the presence of heart failure in our patients with CAD.

Keywords: Adipocyte fatty-acid binding protein, Coronary artery disease, Single-photon emission computed tomography

\section{Background}

Insulin resistance is closely associated with cardiovascular disease and heart failure (HF), and dysregulated adipokines, which are mainly released from adipose tissues, suggesting possible links between these conditions [1,2]. These adipokines, including adiponectin, resistin, and leptin, are known to mediate important

\footnotetext{
* Correspondence: wuyw0502@gmail.com; wsyang@ntu.edu.tw

2Department of Internal Medicine, National Taiwan University Hospital, Taipei, Taiwan

${ }^{4}$ Graduate Institute of Clinical Medicine, College of Medicine, National Taiwan University, No.7, Chung-Shan S. Rd., Taipei 100, Taiwan

Full list of author information is available at the end of the article
}

inflammatory and metabolic responses [3-5]. Adipocyte fatty-acid binding protein (A-FABP), also termed aP2, is one of the most abundant intracellular lipid transport proteins in mature adipocytes and macrophages. However, data from rodents and humans suggest that it is also secreted into the bloodstream by adipose tissue [6]. In animal studies, A-FABP has been shown to regulate many inflammatory cytokines, mediate lipotoxicity and endoplasmic reticulum stress, and lead to endothelial dysfunction by impairing the nitric oxide pathway [7-9]. Recent human studies have confirmed its association with diabetes mellitus, non-alcoholic fatty liver disease, 
and cardiovascular disease. Circulating A-FABP level is also an independent predictor of metabolic syndrome development and coronary heart disease outcomes [10-14].

Two Asian studies showed a positive correlation between circulating A-FABP level and the severity of coronary artery disease (CAD), as determined by coronary angiography $[15,16]$. Tl-201 dipyridamole single-photon emission computed tomography (SPECT) is currently the standard tool in clinical CAD evaluation and demonstrates the extent of myocardial scar and ischemic burden. The aim of our study was to evaluate the correlation of circulating A-FABP levels with SPECT results, left ventricular function, and $\mathrm{HF}$ in CAD patients.

\section{Methods}

\section{Study design}

This cross-sectional study enrolled 170 consecutive patients with CAD from the cardiovascular outpatient clinics at Taoyuan General Hospital and National Taiwan University Hospital Hsin-Chu branch between July 2010 and June 2011. The study was approved by the institutional review board of both hospitals, and written informed consent was obtained from each patient before enrollment. Eligible patients had at least one of the following: old myocardial infarction (> 6 months), coronary revascularization, angiographic evidence of at least $50 \%$ stenosis in 1 or more major coronary arteries, or evidence of ischemia/scar on nuclear stress myocardial perfusion imaging. Patients were excluded if they had evidence of acute inflammatory or infectious disease, decompensated liver disease, end-stage renal disease, active malignancy, acute coronary syndrome, or a stroke within the month before the investigation.

All demographic information, including height, weight, waist measurements, cardiovascular risk factors, comorbid conditions, and a list of current medications were obtained from the patients' medical records. Twodimensional echocardiography and Tl-201 dipyridamole SPECT, as previously described [17], were performed in all participants. Left atrial dimension (LAd), left ventricular end-diastolic dimension (LVEDd), left ventricular end-systolic dimension (LVESd), interventricular septal dimension (IVSd), and left ventricular ejection fraction (LVEF) were evaluated and recorded in a blinded manner. Regional myocardial uptake was normalized and assessed using the 17-segment model and a semiquantitative scoring system of defect severity with a 5 -point scoring system $(0=$ normal, $1=$ equivocal, $2=$ moderate, 3 = severe, and $4=$ apparent absence of tracer uptake) and extent, as recommended by the American Society of Nuclear Cardiology [18]. Summed scores were calculated from the segmental scores, including a summed rest score (SRS; the sum of the 17 segmental rest scores) and summed stress score (SSS; the sum of the 17 segmental stress scores). A summed difference score (SDS; the difference between SSS and SRS) was also calculated. CAD severity, which was determined by SSS, was considered normal if the SSS $<4$, mildly abnormal if the SSS was between 4 and 8 , and moderately to severely abnormal if the SSS $>8$. Image interpretation according to these definitions was performed by 2 experienced readers. Divergent interpretations were classified by consensus. The HF diagnosis was based on the criteria established in the American College of Cardiology/ American Heart Association 2005 Guideline Update for the Diagnosis and Management of HF [19].

Laboratory examinations included renal function, fasting glucose, lipid profiles, high-sensitivity C-reactive protein (hsCRP), and $\mathrm{N}$-terminal pro-brain natriuretic peptide (NT-proBNP). Glomerular filtration rate (GFR) was estimated using the formula from Modification of Diet in Renal Disease (MDRD). Serum A-FABP (BioVendor Laboratory Medicine, Inc. Brno, Czech Republic) and adiponectin concentrations (B-Bridge International, Inc., Cupertino, CA, USA) were analyzed by an enzyme-linked immunosorbent assay method, according to the manufacturer's instructions.

\section{Statistical analysis}

Data are reported as mean \pm SD for normal distributions or as median with interquartile ranges for skewed variables. Data that were not normally distributed were logarithmically transformed before analysis. Group comparisons were performed by 2-sample $t$ test. Univariate relationships between A-FABP level and clinical variables, serum biomarkers, and parameters derived from echocardiography and SPECT were assessed using Pearson's correlation coefficient ( $r$ ). Differences in serum A-FABP concentrations across SSS were compared by one-way analysis of variance, followed by the Bonferroni post-hoc test. To determine the independent predictors of myocardial perfusion abnormality and HF, the various parameters were included in multiple logistic regression analyses (ordered logistic regression for SSS). Analyses were performed using the STATA statistical software (release 10.0, StataCorp, College Station, TX, USA). All statistical tests were two-sided, where $P<0.05$ was considered statistically significant.

\section{Results}

The characteristics of all the participants are shown in Table 1 . The mean age was 66.8 years, and $73 \%$ of the patients were male. The prevalence of hypertension and diabetes were $43 \%(n=73)$ and $21 \%(n=36)$, respectively. Forty-six patients (27\%) had a history of myocardial infarction. Compared with those with mild CAD $(S S S \leq 8)$, the patients with moderate to severe CAD $(\mathrm{SSS}>8)$ tended to be older, have a higher prevalence of 
Table 1 Characteristics of coronary artery disease patients

\begin{tabular}{|c|c|c|c|c|}
\hline Parameter & $\begin{array}{c}\text { All } \\
(n=170)\end{array}$ & $\begin{array}{c}\text { Mild CAD } \\
\text { (SSS } \leq \mathbf{8}, \mathrm{n}=\mathbf{8 8})\end{array}$ & $\begin{array}{c}\text { Moderate-severe CAD } \\
\quad(\mathrm{SSS}>\mathbf{8}, \mathbf{n}=\mathbf{8 2} \text { ) }\end{array}$ & $P$ value \\
\hline Age (yr) & $65.7 \pm 13.6$ & $64.0 \pm 13.1$ & $67.6 \pm 13.9$ & 0.09 \\
\hline Male gender (\%) & $115(68 \%)$ & $55(63 \%)$ & $50(73 \%)$ & 0.14 \\
\hline Body mass index $\left(\mathrm{kg} / \mathrm{m}^{2}\right)$ & $24.9 \pm 3.7$ & $24.9 \pm 3.5$ & $24.9 \pm 4.1$ & 0.99 \\
\hline Waist (cm) & $85 \pm 11$ & $86 \pm 12$ & $84 \pm 11$ & 0.41 \\
\hline Hypertension (\%) & $73(43 \%)$ & $36(41 \%)$ & $37(45 \%)$ & 0.58 \\
\hline Diabetes mellitus (\%) & $36(21 \%)$ & $14(16 \%)$ & $22(27 \%)$ & 0.08 \\
\hline Smoking (\%) & $43(25 \%)$ & $14(16 \%)$ & $29(35 \%)$ & 0.004 \\
\hline LVEF & $0.61 \pm 0.16$ & $0.68 \pm 0.13$ & $0.53 \pm 0.16$ & $<0.0001$ \\
\hline Creatinine $(\mathrm{mg} / \mathrm{dL})$ & $1.13 \pm 0.45$ & $1.03 \pm 0.34$ & $1.22 \pm 0.53$ & 0.005 \\
\hline Fasting glucose (mg/dL) & $116 \pm 45$ & $110 \pm 42$ & $123 \pm 47$ & 0.07 \\
\hline Total cholesterol (mg/dL) & $186 \pm 47$ & $184 \pm 38$ & $189 \pm 57$ & 0.58 \\
\hline $\mathrm{HDL}-\mathrm{C}(\mathrm{mg} / \mathrm{dL})$ & $48 \pm 16$ & $51 \pm 18$ & $44 \pm 12$ & 0.006 \\
\hline LDL-C (mg/dL) & $108 \pm 34$ & $105 \pm 26$ & $111 \pm 41$ & 0.25 \\
\hline $\operatorname{ALT}(\mathrm{U} / \mathrm{L})$ & $29 \pm 19$ & $27 \pm 19$ & $30 \pm 20$ & 0.18 \\
\hline $\operatorname{hsCRP}(\mathrm{ug} / \mathrm{mL})^{*}$ & $2.3(1.1,8.2)$ & $1.8(0.6,4.6)$ & $3.0(1.7,11.9)$ & 0.0005 \\
\hline NT-proBNP (ng/L)* & $107(42,797)$ & $63(38,127)$ & $797(129,2572)$ & $<0.0001$ \\
\hline Adiponectin (mg/L)* & $7.6(5.2,12.3)$ & $7.4(5.0,10.0)$ & $7.7(5.3,15.7)$ & 0.13 \\
\hline A-FABP $(\mathrm{ng} / \mathrm{mL})^{*}$ & $26.2(17.2,40.1)$ & $21.1(16.2,33.8)$ & $32.4(19.7,48.5)$ & 0.002 \\
\hline \multicolumn{5}{|l|}{ Medications } \\
\hline ACEi/ARBs & $101(59 \%)$ & $34(39 \%)$ & $67(82 \%)$ & $<0.0001$ \\
\hline Beta-blockers & $57(34 \%)$ & $23(26 \%)$ & 34 (41\%) & 0.03 \\
\hline CCBs & $39(23 \%)$ & $24(27 \%)$ & $15(18 \%)$ & 0.16 \\
\hline Diuretics & $51(30 \%)$ & $14(16 \%)$ & $37(45 \%)$ & $<0.0001$ \\
\hline Statins & $36(21 \%)$ & $12(14 \%)$ & $24(29 \%)$ & 0.01 \\
\hline Metformin & $12(7 \%)$ & $5(6 \%)$ & 7 (9\%) & 0.47 \\
\hline
\end{tabular}

Values are expressed as mean \pm S.D., median $\left(25^{\text {th }}-75^{\text {th }}\right.$ percentile), or $\mathrm{n}$ (percentage).

* Logarithmically transformed before analysis.

ACEi/ARBs, angiotensin-converting enzyme inhibitor / angiotensin II receptor blockers; A-FABP, adipocyte fatty acid-binding protein, ALT, alanine aminotransferase; CCBs, calcium channel blockers; HDL-C, high-density lipoprotein cholesterol; hsCRP, high-sensitivity C-reactive protein; LDL-C, low-density lipoprotein cholesterol; LVEF, left ventricular ejection fraction.

diabetes, and have a lower LVEF. The serum creatinine, hsCRP, NT-proBNP, and A-FABP levels were also significantly higher in the patients with moderate to severe CAD. Among these patients, $34 \%(n=58)$ had a clinical diagnosis of heart failure with New York Heart Association (NYHA) functional class II to IV. The patients with HF had significantly higher serum NT-proBNP and hsCRP levels than those without $\operatorname{HF}(P<0.001$ and $P<0.003$, respectively). Adiponectin and A-FABP concentrations were also significantly higher in the patients with HF (HF vs. non-HF: median level, adiponectin, 12.1 vs. $6.5 \mathrm{mg} / \mathrm{L}$, $P<0.0001$; A-FABP, 34.8 vs. $21.0 \mathrm{ng} / \mathrm{mL}, P<0.0001$ ).

Table 2 shows the results of the correlation analysis between the sex-adjusted A-FABP level and other clinical parameters. In the overall patient population, after the adjustment for sex, the A-FABP level was positively correlated with age, body mass index (BMI), waist circumference, levels of serum creatinine, fasting glucose, high-density lipoprotein cholesterol (HDL-C), hsCRP, adiponectin, and NT-proBNP, but negatively correlated with MDRD-GFR. Among the parameters derived from echocardiography, A-FABP level was inversely correlated with LVEF $(\mathrm{r}=-0.33, P<0.0001)$, but positively correlated with LVEDd, LVESd, LAd, and IVSd.

In the analysis of SPECT results, SRS, SSS, and SDS were regarded as indicators of myocardial scar, CAD severity, and ischemic burden, among which SSS and SDS showed a positive correlation with A-FABP levels $(r=0.19$ and 0.17 , respectively; Table 2$)$. The patients with a high scar burden (SRS $\geq 4$ ) had significantly higher A-FABP levels (median, 31.6 vs. $21 \mathrm{ng} / \mathrm{mL}$, $P=0.006$ ) than those with low or no scar burden (SRS $<4)$. Compared with those with normal SSS (SSS $<4$ ), a 
Table 2 Correlation of sex-adjusted A-FABP levels with biochemical parameters, echocardiographic indexes and myocardial perfusion abnormalities

\begin{tabular}{|c|c|c|}
\hline & $r$ & $\mathbf{P}$ \\
\hline Age & 0.33 & $<0.0001$ \\
\hline Body mass index & 0.31 & 0.0001 \\
\hline Waist circumference & 0.36 & $<0.0001$ \\
\hline GFR & -0.48 & $<0.0001$ \\
\hline Fasting glucose & 0.18 & 0.024 \\
\hline Total cholesterol & 0.10 & 0.186 \\
\hline $\mathrm{HDL}-\mathrm{C}$ & -0.20 & 0.013 \\
\hline LDL-C & 0.02 & 0.847 \\
\hline hsCRP* & 0.32 & 0.0001 \\
\hline NT-proBNP* & 0.49 & $<0.0001$ \\
\hline Adiponectin* & 0.20 & 0.019 \\
\hline \multicolumn{3}{|l|}{ Echocardiography } \\
\hline LVEF & -0.33 & $<0.0001$ \\
\hline LVEDd & 0.29 & 0.0002 \\
\hline LVESd & 0.35 & $<0.0001$ \\
\hline LAd & 0.33 & 0.0003 \\
\hline IVSd & 0.40 & $<0.0001$ \\
\hline \multicolumn{3}{|l|}{ SPECT } \\
\hline Summed rest score (SRS) & 0.13 & 0.088 \\
\hline Summed stress score (SSS) & 0.19 & 0.013 \\
\hline Summed difference score (SDS) & 0.17 & 0.027 \\
\hline
\end{tabular}

* Logarithmically transformed before analysis. GFR, glomerular filtration rate; HDL-C, high-density lipoprotein cholesterol; IVSd, interventricular septal dimension; LAd, left atrial dimension; LVEDd, left ventricular end-diastolic dimension; LVESd, left ventricular end-systolic dimension; LVEF, left ventricular ejection fraction; LDL-C: low-density lipoprotein cholesterol.

trend of higher A-FABP levels was observed in the patients with more extensive CAD (SSS $\geq 4, P=0.008$; Figure 1). Multivariate ordered logistic regression, using SSS (normal, mildly abnormal, and moderately to severely abnormal) as dependent variable, was performed to investigate the association of A-FABP level and myocardial perfusion abnormality. After adjustment for age, sex, hypertension, BMI, smoking status, level of fasting glucose, creatinine, low-density lipoprotein cholesterol (LDL-C), and hsCRP, A-FABP level was still an independent predictor of higher SSS (odds ratio, 1.30 per $10-\mathrm{ng} / \mathrm{mL}$ increase; $95 \%$ confidence interval $[\mathrm{CI}], 1.01-$ $1.69 ; P=0.048)$. However, we further analyzed the association between A-FABP level and myocardial perfusion abnormalities in the subgroups of the patients with and without HF. The differences in A-FABP levels between patients with high and low SSS, and also SRS, were significantly attenuated in those with concomitant HF (Table 3).

Finally, multiple logistic regression analysis was performed to accurately evaluate the relationship between

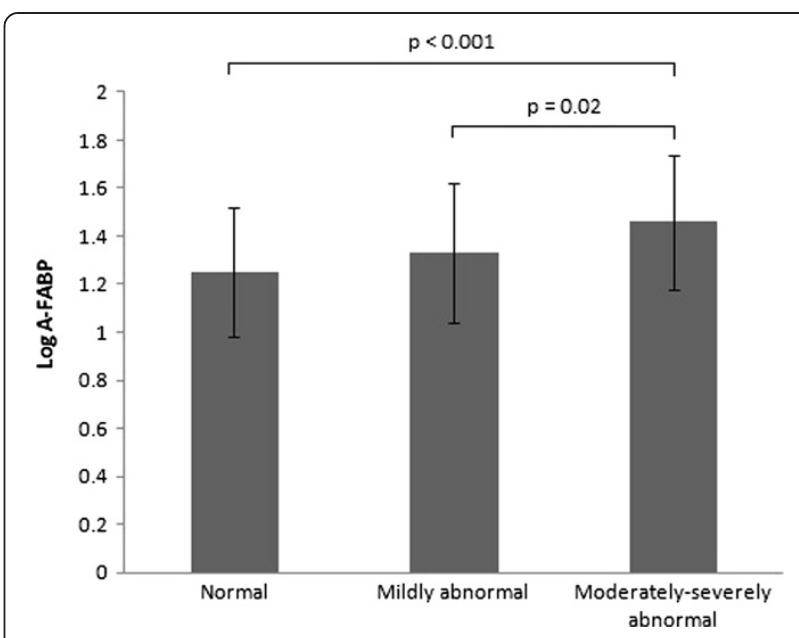

Figure 1 Association between serum A-FABP concentration and coronary artery disease severity determined by summed stress score (SSS). Normal: SSS $<4$, mildly abnormal: $4 \leq$ SSS $\leq 8$,

moderately to severely abnormal: SSS $>8$.

A-FABP level and HF in the subjects with CAD. A-FABP level was also independently associated with the presence of $\mathrm{HF}$, with an odds ratio of 2.71 (95\% CI, 1.23-5.94; $P=0.013$ ) for each $10-\mathrm{ng} / \mathrm{mL}$ increase (Table 4 ).

\section{Discussion}

Our study demonstrated that serum A-FABP levels were associated with CAD severity, as determined by SPECT. We also found that the patients with HF had higher A-FABP levels than those without HF. After multivariate adjustment, A-FABP was an independent predictor of myocardial perfusion abnormalities and HF. However, the correlations between A-FABP level and myocardial perfusion abnormalities were attenuated in the subgroup of patients with HF.

A-FABP expression is known to be a key proinflammatory mediator that links obesity with cardiovascular disease. Data from animal to human studies all support its pathological roles in atherosclerosis. In apoE knockout mice, A-FABP deficiency resulted in a marked reduction of aortic atherosclerotic lesions [20]. In addition, pharmacological inhibition of A-FABP also rendered significant protection against atherosclerotic plaque formation [21]. Depletion of A-FABP expression prevented oxidized LDLinduced foam cell formation by increasing cholesterol efflux and also inhibited IkB kinase/NF-kB activity. This finding further supported the proatherogenic effects of A-FABP in macrophages. In addition, A-FABP inhibited eNOS activation and nitric oxide production in vascular endothelial cells, which led to endothelial dysfunction. This suppressive effect was reversed by treatment with an A-FABP inhibitor [9,22]. In human studies, A-FABP is known to be involved in metabolic syndrome and cardiovascular diseases. Circulating A-FABP levels have been 
Table 3 Serum A-FABP distribution according to summed stress score, summed rest score and heart failure (HF) condition

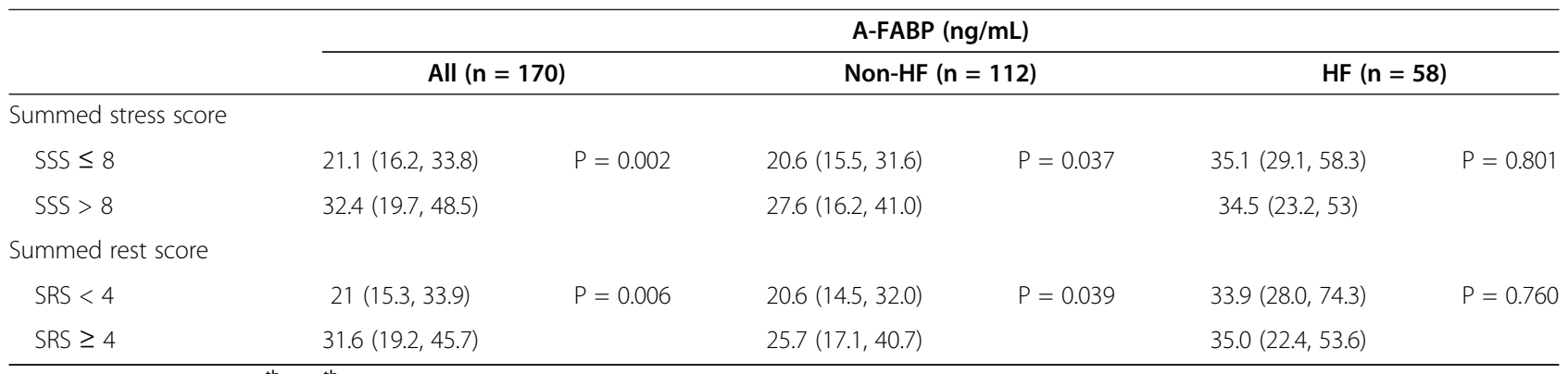

Presented with median $\left(25^{\text {th }}-75^{\text {th }}\right.$ percentile) and logarithmically transformed before analysis.

shown to correlate with the presence of CAD and carotid atherosclerosis, with the number of diseased vessels, and with plaque burden of coronary arteries $[15,16,23,24]$. It is also an important predictor of cardiovascular outcomes in patients with coronary heart disease, acute ischemic stroke, and end-stage renal disease [14,23,25]. Locally expressed A-FABP in atherosclerotic plaques also reduces plaque stability [26].

We also found an association between circulating A-FABP level and metabolic components. A-FABP level showed a positive correlation with waist circumference and fasting glucose level but a negative correlation with HDL-C. A weak correlation was also observed between concentrations of A-FABP and adiponectin, another well-documented insulin resistance marker. The A-FABP concentration also correlated positively with the inflammatory marker hsCRP, as previous studies have demonstrated. There were significant differences in A-FABP levels between men and women. Two Asian studies made different conclusions about the relationship of A-FABP and CAD in different sexes. In our study, the differences in A-FABP levels between patients with mild and severe CAD were consistent, although the differences were more significant in women (median, 44.6 vs. $26.3 \mathrm{ng} / \mathrm{mL}, P=0.0006$ ). Previous studies have also shown that atorvastatin and olmesartan treatment lowered circulating A-FABP levels $[27,28]$. The higher A-FABP levels in our patients treated with statins and angiotensin-converting enzyme inhibitors or angiotensin II receptor blockers might be related to the higher prevalence of metabolic syndrome, severe $\mathrm{CAD}$, and advanced HF. It is interesting that both $\mathrm{HF}$ and non-HF subgroup patients taking thiazide diuretics had significantly higher A-FABP concentrations. Thus, the effects of thiazide diuretics, which are known to cause metabolic abnormalities, on serum A-FABP concentrations would be worth investigating in a prospective, interventional study design.

The upregulation of A-FABP expression and other adipokines in HF has also been demonstrated in recent studies $[3,4,29,30]$. However, their exact roles in the pathogenesis of HF remain unclear. The complex neurohormonal and metabolic abnormalities associated with HF have received increased attention. Of note, upregulation of inflammatory cytokines, catecholamines, growth hormone, and catabolic steroids is known to mediate increased lipolysis and insulin resistance [31]. Data from randomized controlled trials of HF have suggested a diabetes prevalence of $8 \%$ to $41 \%$, and insulin resistance is found to correlate with the functional, clinical, and biochemical severity of HF [32]. Most importantly, a recent in vitro study by Lamounier-Zepter et al. demonstrated that A-FABP suppressed the contraction of cardiomyocytes by attenuating intracellular $\mathrm{Ca}^{2+}$ levels [33]. This offered strong evidence that A-FABP might be directly involved in the pathogenesis of HF. In human studies, Mingya et al. [29] demonstrated that serum A-FABP levels were associated with HF severity, as determined by the NYHA classification system, and were positively correlated with NT-proBNP levels in Chinese

Table 4 Multiple logistic regression analysis showing odds ratio for the risk of heart failure in patients with coronary artery disease

\begin{tabular}{|c|c|c|c|c|}
\hline Model & A-FABP (per $10 \mathrm{ng} / \mathrm{mL}$ increase) & OR & $95 \% \mathrm{Cl}$ & $P$ value \\
\hline Model 1 & Adjusting for age and sex & 1.58 & $1.25-1.99$ & $<0.001$ \\
\hline Model 2 & $\begin{array}{l}\text { Adjusting for age, sex, BMl, smoking, hypertension, } \\
\text { fasting glucose, LDL-C, creatinine and hsCRP }\end{array}$ & 2.03 & $1.31-3.14$ & 0.002 \\
\hline Model 3 & $\begin{array}{l}\text { Adjusting for age, sex, BMI, smoking, hypertension, fasting glucose, LDL-C, } \\
\text { creatinine, hsCRP, adiponectin, SSS, SRS, ACEi/ARBs, diuretics and statins use }\end{array}$ & 2.71 & $1.23-5.94$ & 0.013 \\
\hline
\end{tabular}


subjects. A further large-scale prospective study showed that plasma concentration of A-FABP predicted a 1.09-fold higher risk of heart failure during a median follow-up of 10.7 years [30]. In our patients, the moderate correlation between A-FABP and NT-proBNP levels also suggested a link between A-FABP level and HF severity. Because the association between A-FABP level and CAD severity was attenuated in the subgroup of patients with $\mathrm{HF}$ and the predictive value of A-FABP to HF persisted after adjustment for SRS and SSS, we believe that HF-related metabolic disarrangement, rather than CAD severity, may be a more important determinant of A-FABP levels in CAD patients with HF.

Notably, higher serum creatinine levels are observed in moderate to severe CAD, with renal function being the main independent predictor of circulating A-FABP levels. Previous studies have shown a negative relationship between GFR and A-FABP concentration, suggesting that A-FABP might have an important role in the interplay between renal dysfunction and the development of coronary atherosclerosis [34]. Because A-FABP is a low-molecular-weight plasma protein, freely filtered at the glomerulus, a decrease in glomerular function will result in an elevation of A-FABP concentration. In our current study, A-FABP level remained an independent predictor of myocardial perfusion abnormality, even after adjusting for renal function.

There were some limitations in the present study. First, the small number of patients enrolled was inadequate to obtain conclusive data. Second, owing to the cross-sectional design of our study, some conclusions were based on findings from association studies that did not imply a direct causal relationship. Third, the SSS could not accurately indicate the severity of CAD in a small number of patients who underwent percutaneous coronary angioplasty before SPECT analysis. However, the myocardial scar, indicated by SRS, was not affected by whether angioplasty had been performed.

\section{Conclusions}

In our study, the serum A-FABP levels not only were associated with myocardial perfusion abnormalities and left ventricular function, but also predicted the presence of $\mathrm{HF}$ in the CAD patients. In conjunction with previous data, our results confirm the important role of A-FABP in metabolic syndrome, atherosclerosis, and HF. However, a further large-scale, prospective study is needed to confirm its predictive value upon traditional CAD risk factors.

\footnotetext{
Abbreviations

A-FABP: Adipocyte fatty acid-binding protein; BMl: Body-mass index;

CAD: Coronary artery disease; HF: Heart failure; GFR: Glomerular filtration rate;

HDL-C: High-density lipoprotein cholesterol; hsCRP: High-sensitivity C-reactive protein; IVSd: Interventricular septal dimension; LAd: Left atrial dimension;
}

LVEDd: Left ventricular end-diastolic dimension; LVESd: Left ventricular endsystolic dimension; LVEF: Left ventricular ejection fraction; LDL-C: Low-density lipoprotein cholesterol; NT-proBNP: N-terminal pro-brain natriuretic peptide; NYHA: New York Heart Association; SPECT: Single-photon emission computed tomography; SDS: Summed difference score; SRS: Summed rest score; SSS: Summed stress score.

\section{Competing interests}

The authors declared no competing interests.

\section{Authors' contributions}

CLH, YWW, CCW, LL and YSJ conceived the study, participated in study design and coordination. YCW and PYH analyzed the SPECT. CLH, YWW and WSY assisted with the preparation and critical review of this manuscript. All authors read and approved the submitted manuscript.

\section{Acknowledgements}

We are grateful to the colleagues from the Taoyuan General Hospital and the National Taiwan University Hospital Hsin-Chu Branch for referring CAD patients, and acknowledge the technical assistance from Ms. Yu-Shuan Hung.

\section{Author details}

'Department of Internal Medicine, Taoyuan General Hospital, Taoyuan, Taiwan. ${ }^{2}$ Department of Internal Medicine, National Taiwan University Hospital, Taipei, Taiwan. ${ }^{3}$ Department of Nuclear Medicine, National Taiwan University Hospital, Taipei, Taiwan. ${ }^{4}$ Graduate Institute of Clinical Medicine, College of Medicine, National Taiwan University, No.7, Chung-Shan S. Rd., Taipei 100, Taiwan. ${ }^{5}$ Department of Nuclear Medicine and Cardiology Division of Cardiovascular Medical Center, Far Eastern Memorial Hospital, No.21, Sec.2, Nanya S. Rd., Banciao Dist., New Taipei City, Taiwan. ${ }^{6}$ National Yang-Ming University School of Medicine, Taipei, Taiwan. ${ }^{7}$ Department of Internal Medicine, National Taiwan University Hospital Hsin-Chu branch, Hsinchu City, Taiwan. ${ }^{8}$ Department of Nuclear Medicine, National Taiwan University Hospital Hsin-Chu branch, Hsinchu City, Taiwan. ${ }^{9}$ Department of Nuclear Medicine, National Taiwan University Hospital Yun-Lin Branch, Douliou City, Taiwan.

Received: 8 June 2013 Accepted: 15 July 2013

Published: 17 July 2013

\section{References}

1. Mamas MA, Deaton C, Rutter MK, Yuille M, Williams SG, Ray SG, New J, Gibson JM, Neyses L: Impaired glucose tolerance and insulin resistance in heart failure: underrecognized and undertreated? J Card Fail 2010, 16(9):761-768.

2. Bornfeldt KE, Tabas I: Insulin resistance, hyperglycemia, and atherosclerosis. Cell Metab 2011, 14(5):575-585.

3. Baldasseroni S, Mannucci E, Orso F, Di Serio C, Pratesi A, Bartoli N, Marella GA, Colombi C, Foschini A, Valoti P, et al: Adiponectin in outpatients with coronary artery disease: independent predictors and relationship with heart failure. Nutr Metab Cardiovasc Dis 2012, 22(3):292-299.

4. Zhang MH, Na B, Schiller NB, Whooley MA: Association of resistin with heart failure and mortality in patients with stable coronary heart disease: data from the heart and soul study. J Card Fail 2011, 17(1):24-30.

5. Wannamethee SG, Shaper AG, Whincup PH, Lennon L, Sattar N: Obesity and risk of incident heart failure in older men with and without preexisting coronary heart disease: does leptin have a role? J Am Coll Cardiol 2011, 58(18):1870-1877.

6. Xu A, Wang Y, Xu JY, Stejskal D, Tam S, Zhang J, Wat NM, Wong WK, Lam KS: Adipocyte fatty acid binding protein is a plasma biomarker closely associated with obesity and metabolic syndrome. Clin Chem 2006 52(3):405-413

7. Makowski L, Brittingham KC, Reynolds JM, Suttles J, Hotamisligil GS: The fatty acid-binding protein, aP2, coordinates macrophage cholesterol trafficking and inflammatory activity. Macrophage expression of aP2 impacts peroxisome proliferator-activated receptor gamma and IkappaB kinase activities. J Biol Chem 2005, 280(13):12888-12895.

8. Erbay E, Babaev VR, Mayers JR, Makowski L, Charles KN, Snitow ME, Fazio S, Wiest MM, Watkins SM, Linton MF, et al: Reducing endoplasmic reticulum stress through a macrophage lipid chaperone alleviates atherosclerosis. Nat Med 2009, 15(12):1383-1391. 
9. Lee MY, Li H, Xiao Y, Zhou Z, Xu A, Vanhoutte PM: Chronic administration of BMS309403 improves endothelial function in apolipoprotein E-deficient mice and in cultured human endothelial cells. $\mathrm{Br} J$ Pharmacol 2011, 162(7):1564-1576.

10. Toruner F, Altinova AE, Akturk M, Kaya M, Arslan E, Bukan N, Kan E, Yetkin I, Arslan M: The relationship between adipocyte fatty acid binding protein4 , retinol binding protein-4 levels and early diabetic nephropathy in patients with type 2 diabetes. Diabetes Res Clin Pract 2011, 91(2):203-207.

11. Kim YC, Cho YK, Lee WY, Kim HJ, Park JH, Park DI, Sohn Cl, Jeon WK, Kim BI, Park SE, et al: Serum adipocyte-specific fatty acid-binding protein is associated with nonalcoholic fatty liver disease in apparently healthy subjects. J Nutr Biochem 2011, 22(3):289-292.

12. Xu A, Vanhoutte PM: Adiponectin and adipocyte fatty acid binding protein in the pathogenesis of cardiovascular disease. Am J Physiol Heart Circ Physiol 2012, 302(6):H1231-H1240.

13. Xu A, Tso AW, Cheung BM, Wang Y, Wat NM, Fong CH, Yeung DC, Janus ED, Sham PC, Lam KS: Circulating adipocyte-fatty acid binding protein levels predict the development of the metabolic syndrome: a 5-year prospective study. Circulation 2007, 115(12):1537-1543.

14. von Eynatten M, Breitling LP, Roos M, Baumann M, Rothenbacher D, Brenner $\mathrm{H}$ : Circulating adipocyte fatty acid-binding protein levels and cardiovascular morbidity and mortality in patients with coronary heart disease: a 10-year prospective study. Arterioscler Thromb Vasc Biol 2012, 32(9):2327-2335.

15. Doi M, Miyoshi T, Hirohata S, Nakamura K, Usui S, Takeda K, Iwamoto M, Kusachi S, Kusano K, Ito H: Association of increased plasma adipocyte fatty acid-binding protein with coronary artery disease in non-elderly men. Cardiovasc Diabetol 2011, 10:44.

16. Bao Y, Lu Z, Zhou M, Li H, Wang Y, Gao M, Wei M, Jia W: Serum levels of adipocyte fatty acid-binding protein are associated with the severity of coronary artery disease in Chinese women. PLOS One 2011, 6(4):e19115.

17. Wu YW, Yen RF, Chieng PU, Huang PJ: TI-201 myocardial SPECT in differentiation of ischemic from nonischemic dilated cardiomyopathy in patients with left ventricular dysfunction. J Nucl Cardiol 2003, 10(4):369-374.

18. Tilkemeier PL, Wackers FJ: Quality Assurance Committee of the American Society of Nuclear Cardiology: Myocardial perfusion planar imaging. J Nucl Cardiol 2006, 13(6):e91-e96.

19. Bonow RO, Bennett S, Casey DE Jr, Ganiats TG, Hlatky MA, Konstam MA, Lambrew CT, Normand SL, Piña IL, Radford MJ, et al: ACC/AHA clinical performance measures for adults with chronic heart failure: a report of the American College of Cardiology/American Heart Association Task Force on Performance Measures (Writing Committee to Develop Heart Failure Clinical Performance Measures) endorsed by the Heart Failure Society of America. J Am Coll Cardiol 2005, 46(6):1144-1178.

20. Makowski L, Boord JB, Maeda K, Babaev VR, Uysal KT, Morgan MA, Parker RA, Suttles J, Fazio S, Hotamisligil GS, et al: Lack of macrophage fatty-acidbinding protein aP2 protects mice deficient in apolipoprotein $\mathrm{E}$ against atherosclerosis. Nat Med 2001, 7(6):699-705.

21. Furuhashi M, Tuncman G, Görgün CZ, Makowski L, Atsumi G, Vaillancourt E, Kono K, Babaev VR, Fazio S, Linton MF, et al: Treatment of diabetes and atherosclerosis by inhibiting fatty-acid-binding protein aP2. Nature 2007, 447(7147):959-965

22. Aragonès G, Saavedra $P$, Heras M, Cabré A, Girona J, Masana L: Fatty acidbinding protein 4 impairs the insulin-dependent nitric oxide pathway in vascular endothelial cells. Cardiovasc Diabetol 2012, 11:72.

23. Holm S, Ueland T, Dahl TB, Michelsen AE, Skjelland M, Russell D, Nymo SH, Krohg-Sørensen K, Clausen OP, Atar D, et al: Fatty Acid binding protein 4 is associated with carotid atherosclerosis and outcome in patients with acute ischemic stroke. PLoS One 2011, 6(12):e28785.

24. Miyoshi T, Onoue G, Hirohata A, Hirohata S, Usui S, Hina K, Kawamura H, Doi M Kusano KF, Kusachi S, et al: Serum adipocyte fatty acid-binding protein is independently associated with coronary atherosclerotic burden measured by intravascular ultrasound. Atherosclerosis 2010, 211(1):164-169.

25. Furuhashi M, Ishimura S, Ota H, Hayashi M, Nishitani T, Tanaka M, Yoshida H, Shimamoto K, Hotamisligil GS, Miura T, et al: Serum fatty acid-binding protein 4 is a predictor of cardiovascular events in end-stage renal disease. PLoS One 2011, 6(11):e27356.

26. Lee K, Santibanez-Koref M, Polvikoski T, Birchall D, Mendelow AD, Keavney B: Increased expression of fatty acid binding protein 4 and leptin in resident macrophages characterizes atherosclerotic plaque rupture. Atherosclerosis 2013, 226(1):74-81.
27. Miyoshi T, Doi M, Hirohata S, Kamikawa S, Usui S, Ogawa H, Sakane K, Izumi R, Ninomiya $Y$, Kusachi S: Olmesartan reduces arterial stiffness and serum adipocyte fatty acid-binding protein in hypertensive patients. Heart Vessels 2011, 26(4):408-413.

28. Wu YW, Kao HL, Huang CL, Chen MF, Lin LY, Wang YC, Lin YH, Lin HJ, Tzen $\mathrm{KY}$, Yen RF, et al: The effects of 3-month atorvastatin therapy on arterial inflammation, calcification, abdominal adipose tissue and circulating biomarkers. Eur J Nucl Med Mol Imaging 2012, 39(3):399-407.

29. Liu M, Zhou M, Bao Y, Xu Z, Li H, Zhang H, Zhu W, Zhang J, Xu A, Wei M, et al: Circulating adipocyte fatty acid-binding protein levels are independently associated with heart failure. Clin Sci (Lond) 2013, 124 (2):115-122.

30. Djoussé L, Bartz TM, Ix JH, Kochar J, Kizer JR, Gottdiener JS, Tracy RP, Mozaffarian D, Siscovick DS, Mukamal KJ, et al: Fatty acid-binding protein 4 and incident heart failure: the Cardiovascular Health Study. Eur J Heart Fail 2013, 15(4):394-399.

31. Levine B, Kalman J, Mayer L, Fillit HM, Packer MP: Elevated circulating levels of tumor necrosis factor in severe chronic heart failure. N Engl J Med 1990, 323(4):236-241.

32. Witteles RM, Fowler MB: Insulin-resistant cardiomyopathy clinical evidence, mechanisms, and treatment options. J Am Coll Cardiol 2008, 51(2):93-102.

33. Lamounier-Zepter V, Look C, Alvarez J, Christ T, Ravens U, Schunck WH, Ehrhart-Bornstein M, Bornstein SR, Morano I, et al: Adipocyte fatty acidbinding protein suppresses cardiomyocyte contraction: a new link between obesity and heart disease. Circ Res 2009, 105(4):326-334.

34. Iwamoto M, Miyoshi T, Doi M, Takeda K, Kajiya M, Nosaka K, Nakayama R, Hirohata S, Usui S, Kusachi S, et al: Elevated serum adipocyte fatty acidbinding protein concentrations are independently associated with renal dysfunction in patients with stable angina pectoris. Cardiovasc Diabetol 2012, 11:26.

doi:10.1186/1475-2840-12-105

Cite this article as: Huang et al:: Association between serum adipocyte fatty-acid binding protein concentrations, left ventricular function and myocardial perfusion abnormalities in patients with coronary artery disease. Cardiovascular Diabetology 2013 12:105.

\section{Submit your next manuscript to BioMed Central and take full advantage of:}

- Convenient online submission

- Thorough peer review

- No space constraints or color figure charges

- Immediate publication on acceptance

- Inclusion in PubMed, CAS, Scopus and Google Scholar

- Research which is freely available for redistribution 